\title{
Influence of calcium sulphoaluminoferrite on the cement stone structure
}

\author{
Svetlana Samchenko ${ }^{1}$, and Dmitriy Zorin ${ }^{1, *}$ \\ ${ }^{1}$ The Moscow State University of Civil Engineering (National Rresearch University), 26 \\ Yaroslavskoye shosse, Moscow, 125993, Russia
}

\begin{abstract}
Usually to obtain expansive cements sulphoaluminate clinker or mix aluminate clinker with calcium sulphates (gypsum, hemihydrate, anhydrate) are used. This paper deals with the composition and properties of solid solution of calcium sulphoaluminoferrite. It was studied an influence of calcium sulphoaluminoferrite on structure and properties cement phases. For these cements ettringite is an important hydration product. The investigation of hydration and properties of sulphomineral cements shows that ettringite are formed thus providing expansion of cement stone. Study of the hydration processes of the calcium sulfoaluminoferrite mineral in gypsum solution showed that the hydration of fine mineral fractions (less than $28 \mu \mathrm{m}$ ) occurs during partial dissolution with crystallization of small ettringite crystals from solution. Sulphoaluminoferrite mineral is characterized by the growth of large prismatic ettringite crystals with their subsequent cleavage in fractions of 45-63 $\mu \mathrm{m}$. Research showed that for expanding additives based on calcium sulfoaluminoferrite, a polyfraction composition combining only small fractions is preferable.
\end{abstract}

\section{Introduction}

Application of concrete and reinforced concrete structures requires overcoming the difficulties associated with contraction and shrinkage of concrete during solidification and drying. Shrinkage can be so strong that any rigid contraction obstacle, whether spacers reinforcement or concrete aggregate, causes high tensile stresses in the concrete cement stone and leads to the concrete destruction in case of a prolonged shrinkage [1-6].

Recently, considerable attention has been paid to materials that, when added to regular Portland cement, provide non-shrinking, expansive and self-stressing cements [7-12].

Expansive cement during hardening provides an increase of cement stone volume, its compaction, expansion and self-stressing. It is used in housing and civil engineering, in the construction of chemical industry facilities, sewage treatment plants, as well as in the construction of tunnels and subway stations. Expansive cement gives concrete and mortar high water resistance, due to which they are successfully used for monolithic reinforced concrete elements, as well as the manufacture of reinforced concrete products themselves.

\footnotetext{
${ }^{*}$ Corresponding author: dim-z@yandex.ru
} 
High density of concrete based on expansive cements allows them to be used in the construction of oil and gas storage facilities.

The most common way to produce expansive cements is to grind Portland cement clinker together with gypsum and an expanding additive [13-15]. One of these additives is sulfoaluminoferrite clinker [16].

\section{Materials and methods}

To obtain the cohesive material, we used sulfoaluminoferrite clinker (SAFC) and Portland cement clinker (OPC). Physical properties and chemical analysis of clinkers are shown in table 1. Mineralogical composition of cements is presented in table 2.

Table 1. Mineralogical composition of cements

\begin{tabular}{|c|c|c|}
\hline & OPC & SAFC \\
\hline Alite & 67 & 12 \\
\hline Belite & 8 & 30 \\
\hline Tricalcium aluminate & 5 & - \\
\hline Calcium aluminoferrite & 13 & 58 \\
\hline Calcium sulfoferrite & - & - \\
\hline
\end{tabular}

Table 2. Physical and chemical properties of cements and sulfoaluminoferrite clinker

\begin{tabular}{|c|c|c|}
\hline & OPC & SAFC \\
\hline Specific gravity & 3.16 & 2.85 \\
\hline Blaine fineness, cm $/ \mathrm{g}$ & 2700 & 3100 \\
\hline Loss of ignition, \% & 0.21 & 0.51 \\
\hline $\mathrm{SiO}_{2}, \%$ & 22.03 & 14.76 \\
\hline $\mathrm{Al}_{2} \mathrm{O}_{3}, \%$ & 5.15 & 10.87 \\
\hline $\mathrm{CaO}, \%$ & 65.41 & 56.39 \\
\hline $\mathrm{MgO}, \%$ & 1.20 & 2.04 \\
\hline $\mathrm{SO}_{3}, \%$ & 0.34 & 2.39 \\
\hline $\mathrm{Fe}_{2} \mathrm{O}_{3}, \%$ & 4.86 & 13.78 \\
\hline
\end{tabular}

Cohesive material was obtained by replacing part of the Portland cement clinker with sulfoaluminoferrite clinker powder. Portland cement clinker was ground to a Blaine fineness of $2,700 \mathrm{~cm}^{2} / \mathrm{g}$. Sulfoaluminoferrite clinker was ground to the fineness of $3,100 \mathrm{~cm}^{2} / \mathrm{g}$. Two-water gypsum was milled separately to the fineness of $3,500 \mathrm{~cm}^{2} / \mathrm{g}$. Sulfoaluminoferrite clinker powder was ground to fractions $>80 \mu \mathrm{m}, 63-80,45-63,28-45$ and less than $28 \mu \mathrm{m}$. The mixtures were prepared by mixing the components in the ratio OPC-clinker $-80 \%$, SAFC (of a certain fraction) $-10 \%$, and gypsum $-10 \%$. Finished cements were closed with water at $\mathrm{W} / \mathrm{C}$ ratio $=0.4$, samples were solidified from the cement test, which hardened under normal conditions for 1, 3, 7, 14 and 28 days, and then tested for strength and expansion. The samples were also subjected to physicochemical analysis. Strength tests were carried out according to GOST 30744-2001. Formation of cement stone cohesive material structure was studied using scanning electron microscopy (SEM).

Effect of the expanding component dispersion on the resulting ferruginous ettringite morphology and on the cohesive material properties was studied. To avoid the effect of gypsum dispersion, the samples were tempered with a saturated gypsum solution, after which they hardened for 6, 12 and 24 hours, as well as for 3, 7, 14 and 28 days, and were studied using various physicochemical methods. Amount of created ferruginous ettringite was determined by the chemical method. 


\section{Results}

The effect of the expanding component dispersion on the resulting ettringite morphology was studied using the sulfoaluminoferrite clinker $\mathrm{C}_{4.4} \mathrm{AF}_{0.4}$ mineral $\left(4.4 \mathrm{CaOAl}_{2} \mathrm{O}_{3} \mathrm{Fe}_{2} \mathrm{O}_{3} 0.4 \mathrm{CaSO}_{4}\right)$. For this, it was ground to fractions $>80 \mu \mathrm{m}, 63-80,45-63$, 28-45 and less than $28 \mu \mathrm{m}$.

Research results showed that the smaller the initial hydrated grains of the SAFC mineral, the faster it hydrates, as evidenced by an increase in the hydration degree according to the XRD data, the results are presented in table 3.

Table 3. The characteristic of the process of sulfoaluminoferrite mineral hydration for different fractions

\begin{tabular}{|l|c|c|c|}
\hline $\begin{array}{l}\text { Grain size, } \\
\mu \mathrm{m}\end{array}$ & $\begin{array}{l}\text { Time of hydration, } \\
\text { days }\end{array}$ & $\begin{array}{l}\text { Degree of hydration } \\
\text { (X-ray), \% }\end{array}$ & $\begin{array}{l}\text { Amount of ferrous } \\
\text { ettringite }\end{array}$ \\
\cline { 2 - 4 } & 0,25 & 42,1 & 54,6 \\
\cline { 2 - 4 } & 0,5 & 62,1 & 63,6 \\
\cline { 2 - 4 } & 1 & 72,9 & 71,2 \\
\hline \multirow{5}{*}{$28-45$} & 3 & 76,9 & 72,8 \\
\cline { 2 - 4 } & 0,25 & 39,8 & 41,3 \\
\cline { 2 - 4 } & 0,5 & 61,7 & 62,3 \\
\hline \multirow{5}{*}{$45-63$} & 1 & 74,1 & 70,2 \\
\cline { 2 - 4 } & 3 & 81,7 & 73,4 \\
\cline { 2 - 4 } & 0,5 & 34,2 & 51,9 \\
\hline \multirow{5}{*}{$63-80$} & 1 & 55,3 & 60,7 \\
\cline { 2 - 4 } & 3 & 69,1 & 70,4 \\
\cline { 2 - 4 } & 0,5 & 25,6 & 42,8 \\
\cline { 2 - 4 } & 1 & 45,3 & 59,8 \\
\hline \multirow{5}{*}{$>80$} & 3 & 62,6 & 65,1 \\
\cline { 2 - 4 } & 7 & 79,7 & 72,8 \\
\cline { 2 - 4 } & 1 & 36,5 & 63,2 \\
\cline { 2 - 4 } & 3 & 47,2 & 64,8 \\
\cline { 2 - 4 } & 7 & 64,3 & 70,9 \\
\hline
\end{tabular}

Calcium sulfoaluminoferrites hydrate rather slowly. Saturation of the liquid phase with calcium ions during hydration reaches a maximum in small fractions $(45-63,28-45$ and less than $28 \mu \mathrm{m}$ ) by 6 hours, and by 24 hours - in large fractions (Fig. 1). Decrease in the concentration of $\mathrm{SO}_{4}{ }^{2-}$ ions indicates the formation of ettringite crystals (Fig. 2). Their number in the field of view per $1 \mathrm{~mm}^{2}$ of a glass slide is approximately the same for small fractions, and the length of resulting small fibrous crystals is comparable with their diameter.

Study of the hydration processes of the calcium sulfoaluminoferrite mineral in gypsum solution showed that the hydration of fine mineral fractions (less than $28 \mu \mathrm{m}$ ) occurs during partial dissolution with crystallization of small ettringite crystals from solution. The diameter of crystals does not exceed 1-3 $\mu \mathrm{m}$, and their length is $15-30 \mu \mathrm{m}$ (Fig. 3. a) 


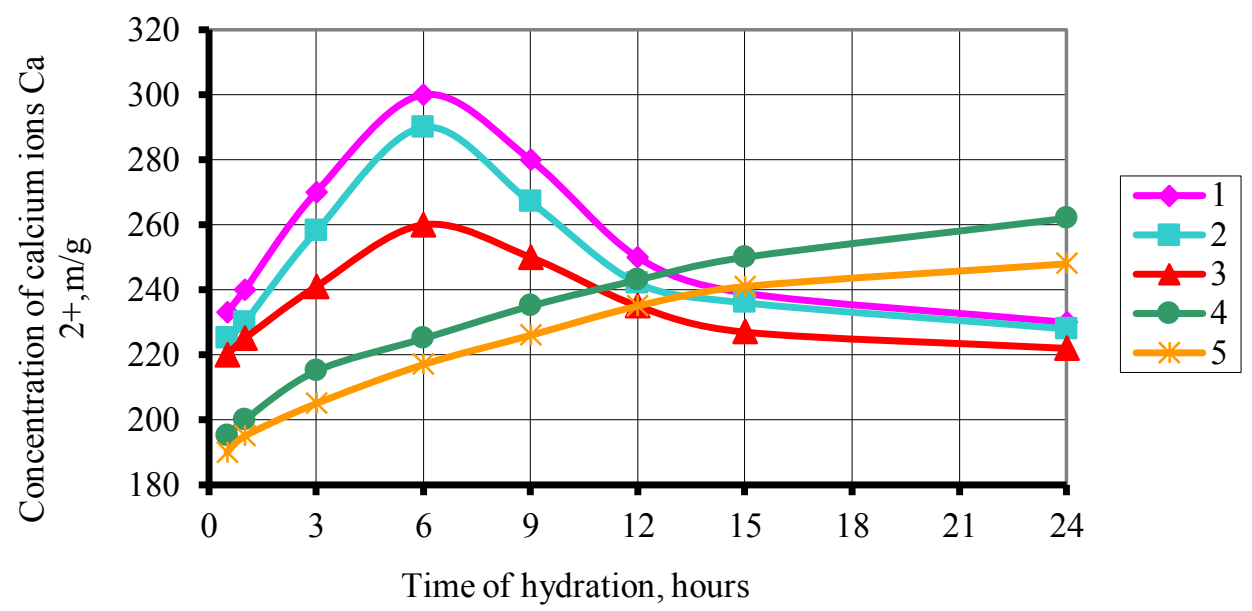

Fig. 1. Concentration ions $\mathrm{Ca}^{2+}$ и $\mathrm{SO}_{4}{ }^{2-}$ in solutions mineral $4.4 \mathrm{CaOAl}_{2} \mathrm{O}_{3} \mathrm{Fe}_{2} \mathrm{O}_{3} 0.4 \mathrm{CaSO}_{4}(1-<28$ $\mu \mathrm{m} ; 2-28-45 \mu \mathrm{m} ; 3-45-63 \mu \mathrm{m} ; 4-63-80 \mu \mathrm{m} ; 5->80 \mu \mathrm{m})$

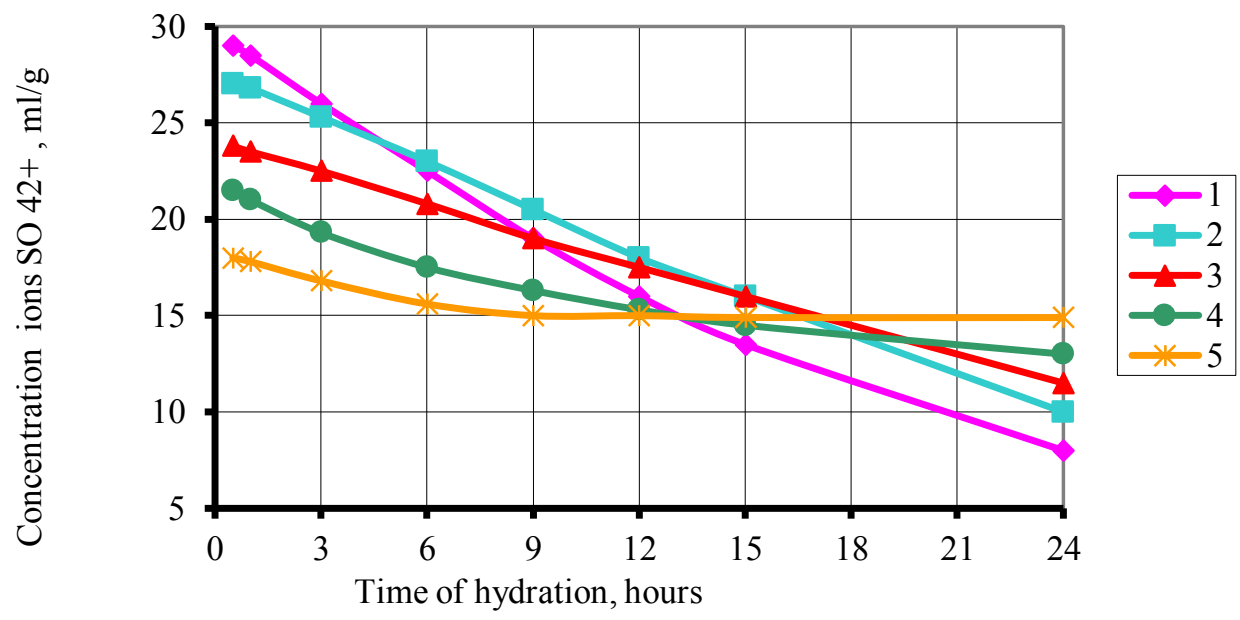

Fig. 2. Concentration ions $\mathrm{Ca}^{2+}$ и $\mathrm{SO}_{4}{ }^{2-}$ in solutions mineral $4.4 \mathrm{CaOAl}_{2} \mathrm{O}_{3} \mathrm{Fe}_{2} \mathrm{O}_{3} 0.4 \mathrm{CaSO}_{4},(1-<28$ $\mu \mathrm{m} ; 2-28-45 \mu \mathrm{m} ; 3-45-63 \mu \mathrm{m} ; 4-63-80 \mu \mathrm{m} ; 5->80 \mu \mathrm{m})$

For the $\mathrm{C}_{4.4} \mathrm{AF} \overline{\mathrm{S}}_{0.4}$ mineral, with a dispersion of 45 to $63 \mu \mathrm{m}$, intensive crystal growth is observed after 24 hours, both from the solution and around the initial grains of mainly acicular habitus (Fig. 3. b) of size $l=60-65 \mu \mathrm{m}$ with diameter $\mathrm{d}=3 \mu \mathrm{m}$. Crystallization of prismatic habitus ettringite $(\mathrm{d}=5 \mu \mathrm{m}, l=80 \mu \mathrm{m})$ from fraction grains $(63-80$ and $>80 \mu \mathrm{m})$ occurs mainly at 3 days of age, followed by the transformation of these crystals into acicular and fibrous forms (Fig. 3. c). Fiber length reaches $l=125 \mu \mathrm{m}$, with $\mathrm{d}=1 \mu \mathrm{m}$. 


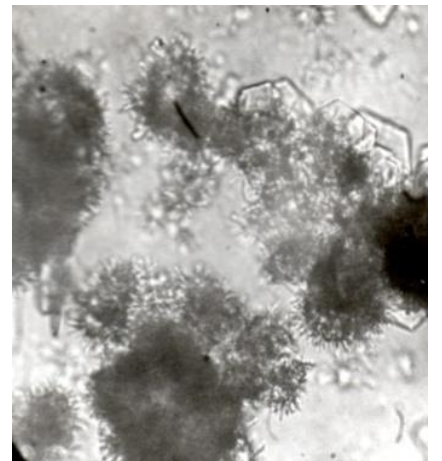

$\mathrm{a}$

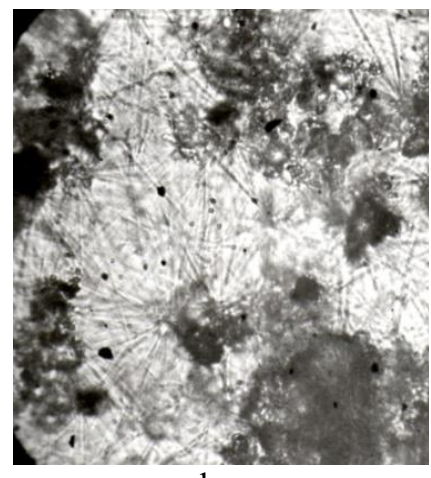

b

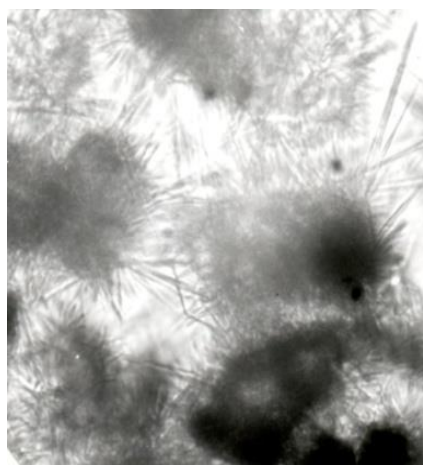

$\mathrm{c}$

Fig. 3. Crystallization of ettringite during hydration of the mineral $C_{4.4} A F \bar{S}_{0.4}$ various factions ( a fraction $28-40 \mu \mathrm{m}, 12$ hours, $\mathrm{b}$ - fraction $45-63 \mu \mathrm{m}, 24$ hours, $\mathrm{c}$ - fraction $63-80 \mu \mathrm{m}, 3$ days)

$\mathrm{C}_{4.4} \mathrm{AF}_{0.4}$ mineral is characterized by the growth of large prismatic ettringite crystals with their subsequent cleavage in fractions of $45-63 \mu \mathrm{m}$.

Since it is not possible to obtain the monofraction composition of the expanding additive under real conditions, studies were performed on the effect of the polyfraction composition of the mineral $\mathrm{C}_{4.4} \mathrm{AF}_{\overline{\mathrm{S}}}{ }_{0.4}$ on the resulting ettringite crystal morphology.

Polyfractional compositions of minerals were prepared by mixing fine and coarse fractions in a ratio of $1: 1$. For the mineral $\mathrm{C}_{4.4} \mathrm{AF} \overline{\mathrm{S}}_{0.4}$, fractions of less than $28 \mu \mathrm{m}$ and a fraction of $28-45 \mu \mathrm{m}$ were chosen, since these fractions are most intensively hydrated in the first 24 hours.

Liquid phase composition and the amount of ettringite were determined by the chemical method. The results are presented in table 4 .

Table 4. The amount of formed ettringite during hydration polyfractional compositions of minerals.

\begin{tabular}{|c|c|c|c|c|}
\hline \multirow{3}{*}{ Mineral } & $\begin{array}{c}\text { Time of } \\
\text { hydration, days }\end{array}$ & $\begin{array}{c}\text { Amount of } \\
\text { ettringite }\end{array}$ & $\begin{array}{c}\text { Habitus of } \\
\text { crystal (d/l) }\end{array}$ & $\begin{array}{c}\text { Morphology of } \\
\text { crystal }\end{array}$ \\
\hline \multirow{3}{*}{$\mathrm{C}_{4,4} \mathrm{AF} \overline{\mathrm{S}}_{0,4}$} & 0.25 & 48.3 & - & - \\
\cline { 2 - 5 } & 0.5 & 59.7 & - & - \\
\cline { 2 - 5 } & 1 & 73.5 & 0.0595 & Prismatic \\
\cline { 2 - 5 } & 0.5 & 26.1 & - & - \\
\cline { 2 - 5 } & 1 & 30.3 & 0.2288 & Short prismatic \\
\hline
\end{tabular}

Such formation of crystals may be due to the fact that a large number of crystallization centers are formed during the hydration of small fractions, while large fractions are hydrated due to the gradual saturation of the liquid phase with a feed solution, large crystals grow (Fig. 4). This is evidenced by the very slow growth of the hydrogen variation of the liquid phase during hydration of the medium (Fig. 5).

The data obtained showed that the amount of ettringite in the first hours and days of hydration is slightly lower than in small fractions, but higher than in large fractions in comparison with the amount formed in monofraction compositions. 


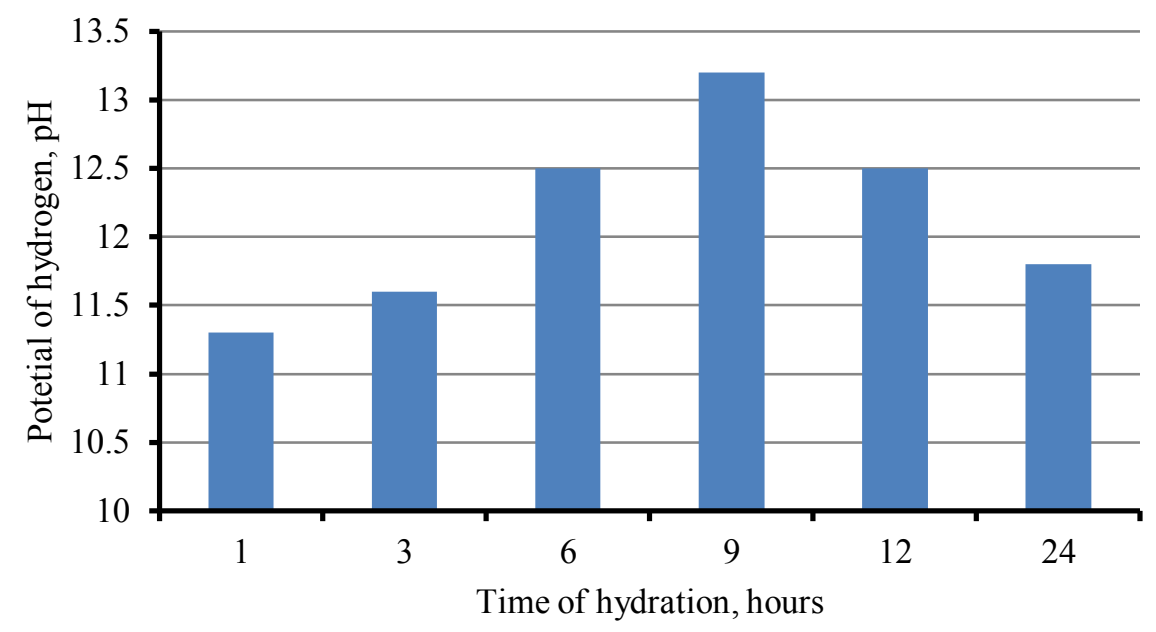

Fig. 4. Medium $\mathrm{pH}$ variation of the liquid phase during hydration

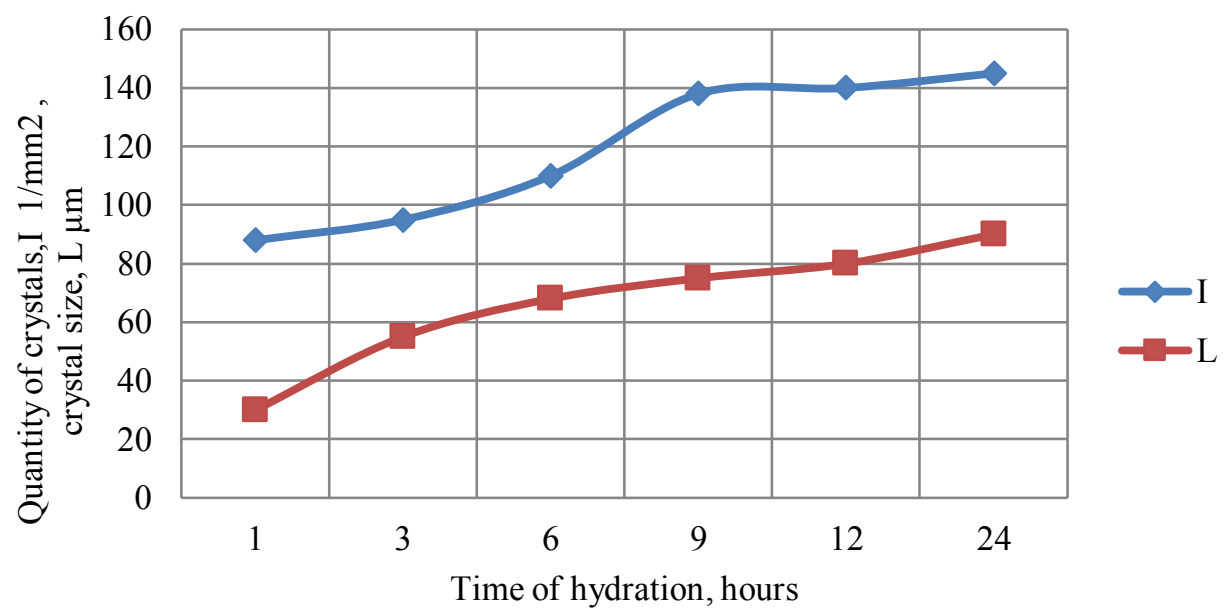

Fig. 5. Initially formed crystals per $1 \mathrm{~mm}^{2}$ of microscope slide for hydration within 24 hours and crystal size.

\section{Discussion}

Hydration study of the $\mathrm{C}_{4.4} \mathrm{AF}_{\mathrm{S}} \overline{\mathrm{S}}_{0.4}$ polyfraction compositions showed that fine fractions provide the formation of crystallization centers, and particles less than 45 microns with constant interaction with the liquid phase cause a gradual crystal growth.

Formation of prismatic or long acicular crystals from medium and coarse fractions of $\mathrm{C}_{4.4} \mathrm{AF} \overline{\mathrm{S}}_{0.4}$ minerals causes system expansion, and the formation of fine crystalline ettringite from fine fractions contributes to the compaction and strengthening of cement stone.

To conclude that for expanding additives based on calcium sulfoaluminoferrite, a polyfraction composition combining only small fractions $(<28 \mu \mathrm{m}$ and $28-45 \mu \mathrm{m})$ is preferable. 
It can be assumed that by varying the fractional composition of the expanding agent in the composition of the composite binder, it is possible to create conditions for the formation of ettringite crystals of different morphology and different amounts, and thereby create a wide range of special cements.

\section{References}

1. J. Zhang, J. Wang, X. Ding, Engineering Fracture Mechanics, 192, pp. 54-76 (2018). https://doi.org/10.1016/j.engfracmech.2018.02.002

2. P. Grassl, H. S. Wong, N. R. Buenfeld, Cement and Concrete Research, 40, 1, pp. 8593 (2010). https://doi.org/10.1016/j.cemconres.2009.09.012

3. H. Costa, E. Júlio, J. Lourenço, Construction and Building Materials, 35, pp. 84-91 (2012). https://doi.org/10.1016/j.conbuildmat.2012.02.052

4. G. Kaklauskas, V. Gribniak, D. Bacinskas, P. Vainiunas, Engineering Structures, 31(6), 1305-1312 (2009). https://doi.org/10.1016/j.engstruct.2008.10.007

5. S.A. Al-Saleh, Construction and Building Materials, 72, 326-332 (2014). https://doi.org/10.1016/j.conbuildmat.2014.06.050

6. W. Piasta, H. Sikora, Construction and Building Materials, 99, 298-307 (2015). https://doi.org/10.1016/j.conbuildmat.2015.09.018

7. Y. Krivoborodov, S. Samchenko, T. Kuznetsova, Refractories and Industrial Ceramics, 59(2), 151-155 (2018). DOI: 10.1007/s11148-018-0197-1

8. D. Zorin, E3S Web of Conferences, 91, 02014 (2019). https://doi.org/10.1051/e3sconf/20199102014

9. L. Mo, M. Deng, A. Wang, Cement and Concrete Composites, 34(3), 377 (2012). https://doi.org/10.1016/j.cemconcomp.2011.11.018

10. R. Gagné, Science and Technology of Concrete Admixtures (2016) https://doi.org/10.1016/B978-0-08-100693-1.00022-9

11. S. Monosi, R. Troli, O. Favoni, F. Tittarelli, Cement and Concrete Composites, 33(4), 485 (2011). https://doi.org/10.1016/j.cemconcomp.2011.01.001

12. J. Bizzozero, C. Gosselin, K. L. Scrivener, Cement and Concrete Research, 56, 190 (2014). https://doi.org/10.1016/j.cemconres.2013. 11.011

13. I. Borisov, A. Grebeniuk, V. Dyukareva, IOP Conference Series: Materials Science and Engineering, 451, 012011(2018). https://doi.org/10.1088/1757$899 X / 451 / 1 / 012011$

14. R. Moradpour, E. Taheri-Nassaj, T. Parhizkar, M. Ghodsian, Composites Part B: Engineering, 55, 193-202 (2013). https://doi.org/10.1016/j.compositesb.2013.06.033

15. Z. Liu, W. Hansen, Construction and Building Materials, 121, 429-436 (2016). https://doi.org/10.1016/j.conbuildmat.2016.06.012

16. S. Samchenko, Y. Krivoborodov, D. Zorin, MATEC Web of conferences 106, 03006, (2017). http://dx.doi.org/10.1051/matecconf/201710603006 